Bond University

Research Repository

\title{
Uncomplicated urinary tract infection in women
}

Hoffmann, Tammy C; Bakhit, Mina; Del Mar, Chris

Published in:

BMJ

DOI:

10.1136/bmj.n725

Licence:

CC BY-NC

Link to output in Bond University research repository.

Recommended citation(APA):

Hoffmann, T. C., Bakhit, M., \& Del Mar, C. (2021). Uncomplicated urinary tract infection in women. BMJ, 372 , [n725]. https://doi.org/10.1136/bmj.n725

\section{General rights}

Copyright and moral rights for the publications made accessible in the public portal are retained by the authors and/or other copyright owners and it is a condition of accessing publications that users recognise and abide by the legal requirements associated with these rights.

For more information, or if you believe that this document breaches copyright, please contact the Bond University research repository coordinator. 
10 minute consultation

4

Mina Bakhit ${ }^{1}$

Chris Del Mar ${ }^{1}$

${ }^{1}$ Institute for Evidence-Based Healthcare, Faculty of Health Sciences and Medicine, Bond 13

\section{Correspondence to:}

15 Tammy Hoffmann

16 Institute for Evidence-Based Healthcare

17 Faculty of Health Sciences and Medicine

18 University Drive

19 Bond University

20 Gold Coast, Queensland, Australia 4229

21

22 thoffmann@bond.edu.au

$23+61755955522$

24

25

\section{How this article was created}

We searched Medline and the Cochrane Library to identify published systematic reviews and randomised controlled trials on the diagnosis and management of uncomplicated urinary tract infections, including antibiotic benefits and harms, natural history of the condition, and commonly used alternative treatments (cranberry, urinary alkalisers, non-steroidal antiinflammatory drugs). We included journal articles identified in the references of articles from the initial search. We searched for relevant NICE guidelines on uncomplicated urinary tract infections. We have referred to recent systematic reviews and meta-analyses but have cited individual clinical studies where there is no higher quality of evidence. 
$39 \mathrm{TH}$ and CDM conceived the article and are guarantors. All authors wrote and reviewed the 40 article and created the boxes.

41

42 How patients were involved in the creation of this article

43 We discussed the article with 2 women who have had uncomplicated urinary tract infections

44 and ensured that information was provided about whether alternatives to antibiotics work and that contained Box 5 safety-netting information and prompted that written information be provided.

47

\section{Conflicts of Interest}

49 TH and CDM have received funding from the Australian National Health and Medical

50 Research Council for research on reducing antibiotic resistance for acute infections and for shared decision making, and from the Australian Commission on Safety and Quality in Health Care for the development of shared decision making resources. MB has no competing interests to declare.

\section{Licence}

"The Corresponding Author has the right to grant on behalf of all authors and does grant on behalf of all authors, an exclusive licence (or non exclusive for government employees) on a worldwide basis to the BMJ Publishing Group Ltd to permit this article (if accepted) to be published in BMJ and any other BMJPGL products and sublicences such use and exploit all subsidiary rights, as set out in our licence (https://authors.bmi.com/policies/\#copyright)." 
Vignette/case and introduction

Your next patient is a 32 year old woman who thinks she has a urinary tract infection (UTI). She's passing urine more frequently, has suprapubic pain and dysuria. After two days, it hasn't improved.

This article will outline how to identify uncomplicated UTI in adult non-pregnant women (1865 years) and discuss options with women to help them make an informed decision about its management.

What you should cover

Acute UTIs are very common community infections. They affect most women at least once in their life and far less prevalent among men. ${ }^{1-3}$ Women with an acute UTI present with diverse symptoms that can be burdensome and impact their quality of life. ${ }^{45}$

\section{What questions you should ask}

Take a history to determine risk factors for UTI and differentiate between uncomplicated UTIs and other causes of urinary symptoms. Recurrent UTI (when there are 3 or more UTIs within one year), asymptomatic bacteruria, or infection associated with an indwelling urinary catheter each require a different approach, not covered here. Symptoms and signs are described in box 1. Evidence from diagnostic studies supports the useful diagnostic value of commonly recognised symptoms such as dysuria, haematuria, nocturia, urgency and frequency, as well as those that decrease the probability that the patient has a UTI. Likelihood ratios of these symptoms are listed in box 2 . However, no individual or combination of symptoms can make clinicians completely confident in diagnosing a UTI. Check for red flags suggestive of acute pyelonephritis or sepsis (box 3), which would require immediate management and/or referral to a hospital.

Is examination necessary?

In most cases of low-risk non-pregnant women with UTIs, clinical examination is not required, and the consultation can be safely conducted remotely. However, if the patient is systemically unwell and presents with any red flag symptom, arrange a physical examination. Assess the patient's vital signs (temperature, blood pressure, heart rate, and respiratory rate) for signs of systemic illness or sepsis and palpate the abdomen and the back for flank or suprapubic tenderness. 


\section{Box 1. Questions to ask}

Is the patient experiencing:

- Burning pain while urinating (dysuria)?

- Urge to void immediately (urgency)?

- Passing urine more than usual at night (nocturia)? Or passing urine more frequently in general (frequency)?

- Cloudy urine visible to the naked eye or blood in the urine (haematuria)?

Vaginal discharge and/or vaginal irritation? (these symptoms are suggestive of a vaginal cause of urinary symptoms. Box 4 gives the most common differential diagnoses for UTIs.)

NICE Guidelines state that patients with 2 or 3 of these key symptoms (cloudy urine, dysuria or new nocturia) are indicative of a UTI. ${ }^{910}$ However a systematic review of 16 studies (3711 patients) ${ }^{11}$ identified visible haematuria (rather than cloudy urine), along with dysuria or new nocturia, as one of the diagnostic symptoms suggestive of UTI.

Is there a history of:

- $\quad$ recent sexual activity? (UTIs are very common among sexually active women. ${ }^{6}$ )

- previous UTI? (The majority of women with a UTI reported a history of UTI infection during the 12 months prior to the current episode. ${ }^{7}$ )

- Using spermicidal agents or a diaphragm? (Spermicidal agents affect the vaginal flora and the diaphragm increase the levels of introital and periurethral colonization with bacteria. ${ }^{8}$ )

- Current pregnancy? (UTIs are common during pregnancy)

- Diabetes? (UTIs are more frequent in patients with type 2 diabetes. ${ }^{6}$ )

\section{Box 2: Summary likelihood ratios (LR) of symptoms suggestive of an uncomplicated UTI 11,12}

Symptoms INCREASING the probability of $\quad$ Symptoms DECREASING the probability of $\mathrm{UTI}$ * UTI **

- Haematuria +LR $1.72(95 \% \mathrm{Cl} 1.30$ to 2.27 )
- A history of vaginal discharge +LR $0.3(95 \% \mathrm{Cl} 0.1$ to 0.9$)$ 
- Dysuria +LR 1.30 (95\% Cl 1.20 to 1.41)

- Nocturia +LR $1.30(95 \% \mathrm{Cl} 1.08$ to 1.56)

- Urgency +LR $1.22(95 \% \mathrm{Cl} 1.11$ to 1.34)

- Frequency +LR $1.10(95 \%$ Cl 1.04 to 1.16 )

* All values reported for threshold of $\geq 10^{2} \mathrm{CFU} / \mathrm{ml}$, therefore probabilities at higher reference standards are lower.

** Values reported for threshold of $\geq 10^{5} \mathrm{CFU} / \mathrm{ml}$
- A history of vaginal irritation +LR 0.2 (95\% Cl 0.1 to 0.9 )

\begin{tabular}{|c|c|}
\hline \multicolumn{2}{|c|}{ Box 3: Red flags for acute pyelonephritis or sepsis } \\
\hline Acute pyelonephritis 613 & Sepsis 14 \\
\hline $\begin{array}{l}\text { - } \text { Flank pain (on the back, at } \\
\text { and/or below level of ribcage) } \\
\text { - Rigors or fever }>37.9^{\circ} \mathrm{C} \\
\text { - Nausea/vomiting } \\
\text { - New/different myalgia, flu-like } \\
\text { illness }\end{array}$ & $\begin{array}{l}\text { - } \geq 21 \text { breaths per minute } \\
\text { - Heart rate: } \geq 91 \text { beats per minute } \\
\text { - Systolic blood pressure } 91-100 \mathrm{mmHg} \\
\text { or less than } 90 \mathrm{mmHg} \text { (i.e. }>40 \mathrm{mmHg} \\
\text { below normal) } \\
\text { - Not passed urine in the past } 12-18 \\
\text { - hours or more } \\
\text { Behaviour changes (acute } \\
\text { deterioration, altered behaviour or } \\
\text { mental state) }\end{array}$ \\
\hline
\end{tabular}

Box 4: Common differential diagnoses of urinary symptoms ${ }^{12}$

- Vaginal infections (e.g., Trichomonas, Candida albicans, Gardnerella)

- Vaginitis: post sexual intercourse, irritants

- Sexually transmitted infections leading to pelvic inflammatory disease

- Vulvovaginal atrophy

\section{What investigations might be needed?}

Urine dipstick tests are the most commonly used point of care test in primary care. ${ }^{15}$ For the laboratory diagnosis of UTI, dipstick results can modestly improve diagnostic precision, but cannot definitively rule out a UTI (Table 1).

\section{Copyright (C) 2021, BMJ Publishing Group Ltd}

Reuse of this manuscript version (excluding any databases, tables, diagrams, photographs and other images or illustrative material included where another copyright owner is identified) is permitted strictly pursuant to the terms of the Creative Commons Attribution-Non Commercial 4.0 International (CC-BY-NC 4.0) 


\begin{tabular}{|c|c|c|c|c|c|}
\hline \multirow[b]{2}{*}{$\begin{array}{l}\text { Number of } \\
\text { these } \\
\text { symptoms } \\
\text { present } \\
\text { (Dysuria, } \\
\text { new } \\
\text { nocturia and } \\
\text { cloudy urine } \\
\text { / haematuria } \\
\text { present) }\end{array}$} & \multicolumn{3}{|c|}{ Dipstick urinalysis } & \multirow[t]{2}{*}{ Possibility of UTI } & \multirow{2}{*}{$\begin{array}{l}\text { Further } \\
\text { testing }\end{array}$} \\
\hline & Nitrite & Leukocyte & RBC & & \\
\hline 2 or 3 & \multicolumn{3}{|c|}{ May not be needed ${ }^{10}$} & Highly likely & $\begin{array}{l}\text { urine } \\
\text { culture } \\
\text { typically } \\
\text { not } \\
\text { needed }\end{array}$ \\
\hline \multirow[t]{6}{*}{1} & + & - & + & Likely* 15 & \multirow{5}{*}{$\begin{array}{l}\text { Send } \\
\text { urine for } \\
\text { culture }^{t}\end{array}$} \\
\hline & + & + & - & & \\
\hline & + & - & - & \multirow[t]{2}{*}{ Likely $^{* *}$} & \\
\hline & - & + & + & & \\
\hline & - & + & - & Equally likely to other diagnosis & \\
\hline & - & - & - & Less likely $^{* * *}$ & $\begin{array}{l}\text { No } \\
\text { indicatio } \\
\mathrm{n} \text { for } \\
\text { urine } \\
\text { culture }\end{array}$ \\
\hline \multicolumn{5}{|c|}{$\begin{array}{l}\text { "Positive predictive value (PPV) of } 92 \% \text { ( } 95 \% \mathrm{Cl} 86 \text { to } 96 \%) \text {, which is the probability } \\
\text { that patients with a positive test have a UTI. Cut-off point on dipstick score } \geq 3 \text { (NPV= } \\
42 \%, 95 \% \mathrm{Cl} \text { not reported). } \\
{ }^{* *} \text { Positive predictive value of } 81 \%(95 \% \mathrm{Cl}=77 \% \text { to } 84 \% \text { ). Cut-off point on dipstick } \\
\text { score } \geq 2 \text { (NPV }=57 \%, 95 \% \mathrm{Cl} 52 \text { to } 62 \%) \\
{ }^{* * *} \text { Negative predictive value (NPV) } 76 \%(95 \% \mathrm{Cl} 66 \text { to } 84 \%) \text { which is the probability } \\
\text { that patients with a negative test truly do not have a UTI. Cut-off point on dipstick score } \\
\geq 1 \\
\text { Urine dipstick cut-off score is based on the sum of nitrite }=2 \text {, leucocyte }=1.5, \mathrm{RBC}= \\
1 .\end{array}$} & \\
\hline
\end{tabular}


${ }^{t}$ Growth cut-off thresholds used to define a UTI can vary (e.g. in some laboratories or countries, it may be $\geq 10^{3} \mathrm{CFU} / \mathrm{ml}$, whereas $\geq 10^{5} \mathrm{CFU} / \mathrm{ml}$ in others). Culture results should also be interpreted with consideration of the severity of signs and symptoms.

112 What you should do

\section{Constructing a shared decision making conversation}

115 In this scenario there are typically two main options that are reasonable to consider:

116 immediate antibiotics or 'wait and see'/delayed prescribing. To enable the patient to make an 117 informed decision about the next steps, the clinician needs to explain both options to the 118 patient, along with the benefits and harms of each, and discuss the patient's preferences 119 before making a shared decision. An approach to this is suggested in box 5 .

121 What is the natural history of a UTI?

122 There is uncertainty around the natural history of uncomplicated UTI, with few studies 123 examining this. In a systematic review of the placebo-controlled arms of three randomised

124 trials (346 placebo group participants), some women appeared to improve or become 125 symptom free spontaneously, with most improvement occurring in the first 9 days. ${ }^{16}$ Over the 126 first 9 days, the percentage of participants who were symptom free or reported improved 127 symptoms was reported as rising to $42 \%$ and by 6 weeks, the percentage was $36 \%$. Some 128 women (39\%) whose symptoms either failed to improve by 6 weeks or became worse over a 129 variable timespan, although the rate of serious complications was low with progression to 130 pyelonephritis was reported in one placebo participant in two of the trials. The low rate of 131 serious complications supports the practice of delayed prescribing, where the patient is 132 given a prescription but advised to wait to see whether symptoms self-resolve before 133 antibiotics are commenced.

135 An estimate of the mean duration of UTI symptoms is provided by an observational study of 136 women with suspected uncomplicated UTI. ${ }^{18}$ In the 511 women who had seen a clinician for 137 their symptoms and rated the initial problem as moderately bad or worse, the mean reported 138 symptom duration was 3.8 days. However, most of the sample took antibiotics, with only 17 139 participants (approximately 3\%) who did not; their reported mean symptom duration was 4.9 140 days. In a related 5-arm randomised trial, a similar duration of moderately bad or worse 141 symptoms was reported: 3.5 days in the immediate antibiotic group and 4.8 days in the 142 delayed (by 48 hours) prescription group. ${ }^{19}$

How long can you 'wait and see' for? 
144 The recommendation in the NICE guideline ${ }^{17}$ is to wait for 2 days before commencing

145 antibiotics. However, there is no evidence provided in support of this timeframe and it is

146 unclear whether the 2-day timeframe is from the start of symptoms or from first consultation.

147 The findings from the systematic review ${ }^{16}$ suggest a 2-day timeframe may be too short, with

148 few participants likely to have improved by then, although about a third may have improved

149 by 7-10 days. There appears to be a lot of uncertainty and variability in the spontaneous

150 recovery timeframe, and when 'wait and see' (delayed prescribing) is discussed with the

151 patient as an option this should include careful description of when to reconsult or

152 commence antibiotics (Box 5).

153 The option of a delayed prescription will be acceptable to many patients. In a cohort study in 154 Amsterdam, 37\% of women who were asked by their general practitioner to delay antibiotic 155 treatment were willing to do so, ${ }^{20}$ however no further details about how this option was 156 presented to patients are provided.

\section{What difference do antibiotics make?}

158 Surprisingly, we could not find a synthesis of antibiotic versus placebo randomised controlled 159 trials for uncomplicated UTI in women under 65 years and therefore no quantification of the 160 effect, perhaps because antibiotic treatment is the traditional management of uncomplicated $161 \mathrm{UTI}$. The extent to which they reduce recovery time, reduce the risk of progression to pyelonephritis, and reduce the risk of recurrence is unknown and not presented in evidencebased clinical practice guidelines.

For the antibiotics most commonly prescribed for UTI (e.g. nitrofurantoin, trimethoprim), there does not appear to be synthesised evidence of their harms. For other antibiotics commonly prescribed in primary care, commonly reported adverse effects include diarrhoea, rash, and nausea. ${ }^{21} 22$ Candidiasis is also possible from antibiotic use. Another harm of antibiotic use is the contribution to antibiotic resistance. This is already particularly a problem for trimethoprim, with existing resistance rates of at least $30 \%$ of Escherichia coli isolates to trimethoprim. ${ }^{23}$ Patients with antibiotic-resistant E. coli UTI are significantly more like to experience clinical response failure (odds ratio [OR] 4.19 (95\% confidence interval 3.27 to $5.37) ; n=2432$ participants). ${ }^{24}$ duration, they are effective in treating the infection. Refer to the current NICE guideline for information about considerations about which antibiotic (guided by local antibiotic resistance patterns, where possible), and recommended dosage and duration. ${ }^{17}$ 


\section{Other treatments}

There is little evidence to support the various over-the-counter medications that patients will often have tried prior to a consultation or concurrently with antibiotics. A 2016 Cochrane review of urinary alkalisers found no randomised trials. ${ }^{25}$ There are no randomised trials of cranberry for the treatment of uncomplicated UTI ${ }^{26} 27$ and a Cochrane review of cranberry products found they did not prevent recurrent urinary tract infections in women any more than placebo or no treatment (RR $0.86,95 \% \mathrm{Cl} 0.71$ to 1.04$){ }^{28}$

A systematic review of the effectiveness of non-steroidal anti-inflammatory drugs (NSAIDs) compared to antibiotics for uncomplicated UTI found five randomised trials. ${ }^{29}$ For the outcome of symptom resolution, three trials found that NSAIDs were inferior to antibiotics; but two trials (smaller, with higher or unclear risk of bias) found no significant difference between the arms. In the groups that received NSAIDs, the percentage of women with symptom resolution by day 3 or 4 ranged from $39 \%-58 \%$. In two of the three trials that reported pyelonephritis, rates were slightly higher in the NSAID group (risk difference of 4 and 5 respectively).

\section{When to reconsult and when to refer}

Women with uncomplicated UTI without risk factors can be typically be assessed remotely.

Box 5 contains safety-netting information to advise patients about when to commence antibiotics (if a delayed prescription was given) and/or reconsult and Box 3 lists the red flags for acute pyelonephritis and sepsis which are likely to require hospital admission.

\section{Box 5: Elements of a shared decision making conversation}

A shared decision making discussion following the diagnosis of an uncomplicated UTI typically involves the following (although it may not be a simple linear process as presented here):

- Outline that there is choice about the next steps and a decision to be made; invite the patient to partner with you in the decision-making to the extent that the patient desires, and reassure any patient who feels overwhelmed or uncertain about the patient's involvement or how to proceed;

- Elicit the patient's expectations about management of the condition. This can include previously tried treatments and experiences, along with fears and concerns (including symptom severity and how it may impact daily tasks); this allows for 
detecting and discussing misperceptions, where necessary, either now or later in the process);

\section{- Explain the options}

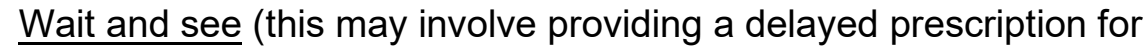
antibiotics and clear information about to when to use it)

Commence antibiotics immediately

- Discuss the benefits and harms of the options (including their likely probability or size)

Describe the natural course of an uncomplicated UTI and that for some women, it will resolve within about a week without taking antibiotics. Also explain that there is uncertainty about exact timeframes and whether your patient will be one of the women who gets better without antibiotics (and that if not, antibiotics may need to be commenced later).

Discuss that antibiotics probably shorten the duration of symptoms, however by taking them, there is the risk of side effects and antibiotic resistance.

Regardless of which option is chosen, provide advice on symptom management (e.g. paracetamol or ibuprofen)

- Provide the opportunity to weigh up the benefits and harms of the options, and consider them in the context of the patient's preferences, values, and circumstances

- Explore if the patient has any questions, is ready to make a decision, or needs further information, time, or the involvement of other people.

- Provide safety-netting information about when to commence antibiotics (if delayed prescription) and/or reconsult

Nausea or vomiting

Rigors

Shivering, chills, and muscle pain

Feeling confused or very drowsy

Not passing urine all day

Blood in the urine

Temperature above $38^{\circ} \mathrm{C}$

Kidney pain in the back or under the ribs

Worsening UTI symptoms

If taking antibiotics, no improvement in UTI symptoms after 48 hours

- Provide written patient information leaflet with summary information ${ }^{30}$ 
- In about a third of women, an uncomplicated UTI may resolve on its own within about 7-10 days, without the need for antibiotics

- The option of 'wait and see' (which typically involves providing a delayed prescription) can be discussed as part of a shared decision making process within the consultation

- Consider pyelonephritis or sepsis and hospital admission in patients who are systemically unwell and have high fever, rigours, nausea/vomiting, flank pain, low blood pressure, high heart rate, high respiratory rate, not passing urine for 12-18 hours, and behaviour change

216 How do you invite patients to share in the decision-making about management of their

217 uncomplicated UTI, including a discussion about their expectations?

How can you facilitate a balanced discussion about the benefits and harms of using antibiotics immediately or adopting a 'wait and see' (delayed prescribing) approach?

\section{References}

224 1. McCormick A, Fleming D, Charlton J, Royal College of General Practicioners, Great

2. Foxman B, Barlow R, D'Arcy H, Gillespie B, Sobel JD. Urinary tract infection: selfreported incidence and associated costs. Ann Epidemiol. 2000 Nov;10(8):509-15.

3. Schappert SM. National ambulatory medical care survey: 1989 summary. Vital Health Stat 13. 1992 Apr(110):1-80.

4. Bærheim KM, Anders. Peeing barbed wire: symptom experiences in women with lower urinary tract infection. Scand J Prim Health Care. 1999;17(1):49-53.

5. Ellis AK, Verma S. Quality of life in women with urinary tract infections: Is benign disease a misnomer? J Am Board Fam Pract. 2000;13(6):392-7.

6. Colgan R, Williams M, Johnson JR. Diagnosis and treatment of acute pyelonephritis

237 7. Foxman B. Epidemiology of urinary tract infections: incidence, morbidity, and economic costs. Dis Mon. 2003 Feb;49(2):53-70. 
8. Fihn SD, Boyko EJ, Chen CL, Normand EH, Yarbro P, Scholes D. Use of spermicidecoated condoms and other risk factors for urinary tract infection caused by staphylococcus saprophyticus. Arch Intern Med. 1998 Feb 9;158(3):281-7.

9. National Institute for Health and Care Excellence. Clinical knowledge summaries: urinary tract infection (lower) - women [Internet]. London: NICE; 2020 Oct. Available from: http://cks.nice.org.uk/urinary-tract-infection-lower-women. Accessed: 06 January 2021.

10. Public Health England. Diagnosis of urinary tract infection: quick reference tool for primary care for consultation and local adaptation [Internet]. London: PHE; 2020 May. Available from: https://assets.publishing.service.gov.uk/government/uploads/system/uploads/attachm ent data/file/927195/UTI diagnostic flowchart NICE-October 2020-FINAL.pdf. Accessed: 06 January 2021.

11. Giesen LG, Cousins G, Dimitrov BD, van de Laar FA, Fahey T. Predicting acute uncomplicated urinary tract infection in women: a systematic review of the diagnostic accuracy of symptoms and signs. BMC Fam Pract. 2010 Oct 24;11(1):78.

12. Bent S, Nallamothu BK, Simel DL, Finn SD, Saint S. Does this woman have an acute uncomplicated urinary tract infection? JAMA. 2002 May;287(20):2701-10.

13. National Institute for Health and Care Excellence. Clinical knowledge summaries:

14. National Institute for Health and Care Excellence. Sepsis: recognition, assessment

15. Little P, Turner S, Rumsby K, Jones R, Warner G, Moore M, et al. Validating the

16. Hoffmann T, Peiris R, Mar CD, Cleo G, Glasziou P. Natural history of uncomplicated urinary tract infection without antibiotics: a systematic review. Br J Gen Pract. 2020 Oct;70(699):e714-e22. prediction of lower urinary tract infection in primary care: Sensitivity and specificity of urinary dipsticks and clinical scores in women. Br J Gen Pract. 2010 Jul;60(576):495500.

17. National Institute for Health and Care Excellence. Urinary tract infection (lower): antimicrobial prescribing [Internet]. London: Nice guideline; 2018 Oct 31 [updated 2019 Jul]. Clinical Guideline [NG109]. Available from: https://www.nice.org.uk/guidance/ng109/resources. Accessed: 06 January 2021. 
18. Little P, Merriman R, Turner S, Rumsby K, Warner G, Lowes JA, et al. Presentation, pattern, and natural course of severe symptoms, and role of antibiotics and antibiotic resistance among patients presenting with suspected uncomplicated urinary tract infection in primary care: observational study. BMJ. 2010 Feb 5;340:b5633.

19. Little P, Moore MV, Turner S, Rumsby K, Warner G, Lowes JA, et al. Effectiveness of five different approaches in management of urinary tract infection: randomised controlled trial. BMJ. 2010 Feb 5;340:c199.

20. Knottnerus BJ, Geerlings SE, Moll van Charante EP, ter Riet G. Women with symptoms of uncomplicated urinary tract infection are often willing to delay antibiotic treatment: a prospective cohort study. BMC Fam Pract. 2013 May 31;14:71.

21. Hansen MP, Scott AM, McCullough A, Thorning S, Aronson JK, Beller EM, et al. Adverse events in people taking macrolide antibiotics versus placebo for any indication. Cochrane Database Syst Rev. 2019 Jan 18;1(1):CD011825.

22. Gillies M, Ranakusuma A, Hoffmann T, Thorning S, McGuire T, Glasziou P, et al. Common harms from amoxicillin: A systematic review and meta-analysis of randomized placebo-controlled trials for any indication. CMAJ. 2015 Jan 6;187(1):E21-E31.

23. Australian Commission on Safety and Quality in Health Care (ACSQHC). Aura 2017: Second australian report on antimicrobial use and resistance in human health [Internet]. Sydney: ACSQHC; 2017. Available from: https://www.safetyandquality.gov.au/publications-and-resources/resourcelibrary/aura-2017-second-australian-report-antimicrobial-use-and-resistance-humanhealth. Accessed: 06 January 2021.

24. Van Hecke O, Wang K, Lee JJ, Roberts NW, Butler CC. Implications of antibiotic resistance for patients' recovery from common infections in the community: a systematic review and meta-analysis. Clin Infect Dis. 2017 Aug 1;65(3):371-82.

25. O'Kane DB, Dave SK, Gore N, Patel F, Hoffmann TC, Trill JL, et al. Urinary alkalisation for symptomatic uncomplicated urinary tract infection in women. Cochrane Database Syst Rev. 2016 Apr 19;4(4):CD010745.

26. Gbinigie O, Allen J, Boylan AM, Hay A, Heneghan C, Moore M, et al. Does cranberry extract reduce antibiotic use for symptoms of acute uncomplicated urinary tract infections (CUTI)? Protocol for a feasibility study. Trials. 2019 Dec 23;20(1):767.

27. Jepson RG, Mihaljevic L, Craig J. Cranberries for treating urinary tract infections.

28. Jepson RG, Williams G, Craig JC. Cranberries for preventing urinary tract infections. Cochrane Database Syst Rev. 2012 Oct 17;10(10):CD001321. 
29. Carey MR, Vaughn VM, Mann J, Townsend W, Chopra V, Patel PK. Is non-steroidal anti-inflammatory therapy non-inferior to antibiotic therapy in uncomplicated urinary tract infections: a systematic review. J Gen Intern Med. 2020 Jun;35(6):1821-9.

314 30. National Institute for Health and Care Excellence. Endorsed resource - TARGET: treating your infection - urinary tract infection (UTI) [Internet]. London: NICE guideline; 2019 February. Clinical Guideline [NG15]. Available from: https://www.nice.org.uk/guidance/ng15/resources/endorsed-resource-target-treatingyour-infection-urinary-tract-infection-uti-4661131357. Accessed: 05 Jan 2021. 